
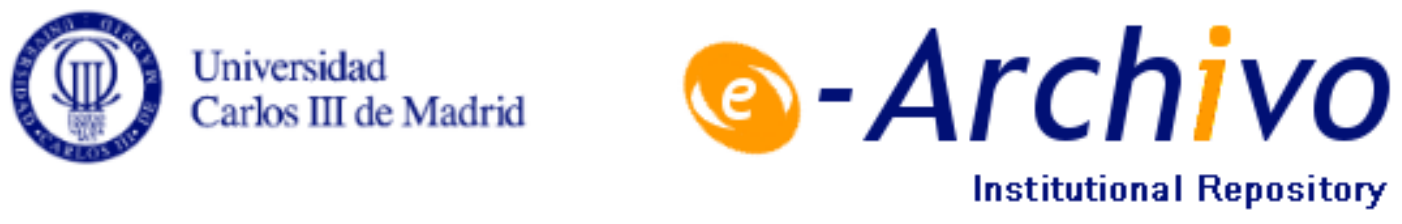

This is a paper submitted to and accepted for publication in:

Beatriz L. Boada, María Jesús L. Boada, M. Ramírez and Vicente Díaz. Study of van roadworthiness considering their maintenance and periodic inspection. The Spanish case. Transportation Letters, 2014, vol. 6, issue 4, pp. 173-184. http://dx.doi.org/10.1179/1942787514Y.0000000023

(C) Taylor \& Francis, 2014 


\title{
STUDY OF VAN ROADWORTHINESS CONSIDERING THEIR MAINTENANCE AND PERIODIC INSPECTION. THE SPANISH CASE
}

\author{
B.L.Boada , M.J.L.Boada, M.Ramirez and V.Diaz \\ Mechanical Engineering Department \\ Institute of Vehicle Safety (ISVA) \\ Carlos III University \\ "Corresponding author: Beatriz L. Boada e-mail: bboada@ing.uc3m.es
}

Abstract. In Europe, traffic road safety has clearly improved due to many factors. One of them is the improvement of the roadworthiness. However, accidents of vans and light goods vehicles have not followed the decreasing tendency of other vehicles.

Several studies suggest that vehicle defects are relevant to the cause of accidents. It would be ideal if vehicle owners continuously kept their vehicles in compliance with the roadworthiness standards. Another important aspect to operate with roadworthy vans is the maintenance programs. It is probable, that many van owners do not adequately maintain their vehicles or the maintenance programs are not sufficient with the Periodic Motor Vehicle Inspections (PMVI) intervals or with the items inspected.

This paper analyses the maintenance schedules and PMVI of vans in order to assess the influence of these parameters in their higher accident rate.

The conclusions provided can enable public administrations to modify enforcement laws, regarding time control of driving and Periodic Motor Vehicle Inspection.

Keywords: Safety, Roadworthiness, maintenance, Periodic Motor Vehicle Inspection, van, light goods vehicles.

\section{Introduction}

Traffic road safety in Spain has clearly improved since 2003 (Aparicio 2011). This fact can be explained by many factors: public investments in road construction, newer vehicle freight, compulsory motor vehicle inspection and introduction of the driving license by points.

Nevertheless, if traffic accidents are analyzed by vehicle categories, it is clear that the accidents of vans and light goods vehicles (LGV henceforth) have not followed this decreasing tendency not only in Spain but also in other European countries due to the growth of courier and ex-press services (Höhnscheid 2006, Bast 2013).

The European Commission (Directorate General Energy and Transport) aware of the socioeconomic importance of road safety has been financing different projects in this field. For instance, the IMPROVER project developed a subproject in 2006 called Impact Assessment of Measures Concerning the Improvement of Road Safety of Light Goods Vehicles (LGV) (Höhnscheid 2006) with the objective of analyzing the problem in order to derive recommendations for the implementation of road safety measures. According to this project vans are mainly used for fast transport of goods in short distances or for the transport of 
equipment for service operations and maintenance. The total stock of LGV in Europe has increased by $36 \%$ between 1999 and 2002 whereas the total vehicle stock grew by $20 \%$ in the same period.

Many factors are known to contribute to traffic accidents but they can usually be categorized into three items: human, environmental and vehicular factors. The TRACE (Traffic Accident Causation in Europe) project (Molinero 2008) presents the accident types for vans in seven European countries. The three most frequent accident types with vans are accidents in carriageways, driving accidents and accidents at sections or inlets. The TRACE project concludes that the most important cause for accidents in vans is inadequate speed and that the influence of fatigue should also be kept in mind.

The Spanish research center INSIA (Martinez 2009) has lead, in 2007, an in-depth study analyzing 225 fatal accidents where a van was involved in rural roads, that is, $68 \%$ of this type of accidents in 2007. The main conclusions of this study were that the van accidents were mainly concentrated from Monday to Friday and their principal causes were driver distraction, fatigue and excessive speed and in $54 \%$ of them the van driver was responsible. Moreover, $12 \%$ of the involved vans had their PMVI out of date and half of the vans involved in the fatal accidents were more than 6 years old.

In 2012, INSIA applied macroscopic models (DRAG and UCM) to analyze and predict the number and severity of both road accidents and victims involving vans (Dadshova 2012). Authors indicate that variables such as exposure, economic factors and road traffic have the highest impact on accident risk.

Van Schoor et al (2001) noticed that there is a lack of consensus in research regarding the usefulness of PMVI. The estimates of the causal role of vehicle defects in traffic crashes range widely from as low as $3 \%$ (van Schoor et al, 2001) to $27 \%$ (Tanaboriboon et al, 2005) in a developing country.

According to Paine (2000), in depth studies suggest that vehicle factors, particularly defects, are "causal, possibly causal or contributory" in at least $12 \%$ of all crashes. Rates for older cars and heavy vehicles tend to be much higher. Vehicles involved in crashes are much more likely to have serious defects than the general population but the defects did not necessarily "cause" the crash. However, serious defects are likely to come into play during the demanding circumstances of a crash and make the crash more severe.

The study presented by Rechnitzer, G et al (2000) also concluded that there was a significant variation in study findings regarding the effectiveness of PMVI programs in reducing defects and crashes. Overall, it would appear that vehicle defects are a contributing factor in $6 \%$ to $50 \%$ of car accidents.

The significance of roadworthiness enforcement by PMVI is a very controversially discussed topic (AUTOFORE 2006, FEMA 2013). However, it is indisputable that the roadworthiness has an effect on the vehicle before, during and after a crash, i.e., during a crash, it is important, that all safety relevant parts, like restraints or airbags, work properly (Krueger 2005). 
It is thus widely accepted that the proportion of crashes in which vehicle defects play any role is also not easy to estimate, and will be underestimated by a significant degree in official crash statistics, as police attending a crash normally do not have the time, training, or motivation to examine a vehicle thoroughly.

The latest research on this subject was lead at the Monash University Accident Research Centre (Keall et al, 2012). Analysis were conducted on crash and licensing data from New Zealand in order to analyze the safety benefits and the reductions in safety-related vehicle faults associated with the increase from annual to biannual inspections that occur six years after the car's manufacture date. The logistic regression analysis estimated that the crash rate decreased by $8 \%$ with a $95 \%$ confidence interval. The decrease in the rate of vehicle faults was estimated to be $13,5 \%$ (with a $95 \% \mathrm{Cl}$ ) associated with the switch from annual to 6-monthly inspections. The proportion of vehicle faults prevented is likely to be at least maintained over the vehicle age range of 7-20 years, suggesting that the resultant safety benefits would also be maintained. The confidence interval for the drop in crash rate was wide, showing considerable statistical uncertainty about the precise size of the drop.

Another important aspect to operate with roadworthy vans is the maintenance programs. It is probable, that many van owners do not adequately maintain their vehicles or the maintenance programs are not sufficient with the PMVI intervals or with the items inspected.

The main objective of the paper is to assess the van characteristics with respect to other types of vehicles, as passenger vehicles or heavy vehicles, in terms of mobility, defects detected in periodic inspections and maintenance levels, in order to compare them with the defects detected in crash damaged vehicles. In this paper, the results regarding the maintenance and roadworthiness are presented and analyzed. The conclusions provided can enable the public administrations to modify the enforcement laws, regarding PMVI (Periodic Motor Vehicle Inspection).

\section{Periodic Motor Vehicle Inspection Regulation}

In 1977 the European Community (EC) adopted a Directive to test roadworthiness for motor vehicles, periodically amended and last revised in 2009 (Directive 2009/40). The Directive sets out a detailed list of all items, which must be checked on a vehicle when it is inspected, as well as the periodicity of the inspections. In the United States, each State is responsible for the PMVI programs and some jurisdictions do not conduct vehicle safety inspection programs, although they are highly recommended by the American Association of Motor Vehicle Administrators (AAMVA) and the National Highway Traffic Administration (NHTSA).

In Spain, PMVI is carried out by private companies that have to be accredited under ISO-EN 17020 Standard as inspection bodies. The Ministry of Industry and Energy publishes a Manual for the Inspection Procedure during the PMVI, an exhaustive guideline of all the components to be inspected, organized by the items listed below and recommended in Annex II of Directive 2009/40. The rejection criteria for each vehicle category are also indicated in the manual:

- Item 1: Identification 
- Item 2: External conditioning, car body and chassis

- Item 3: Interior conditioning

- Item 4: Lights and signal lights

- Item 5: Emissions

- Item 6: Brakes

- Item 7: Steering

- Item 8: Axis, wheels, tires and suspension

- Item 9: Engine and transmission

- Item 10: Others

For each item inspected, results are stated according to the following code:

- ND: No defect; inspected and found to be in order.

- SD: Small defect; defect should be repaired, but the car does not have to be inspected again.

- SSD: Serious defect; defect should be repaired and the car should be reinspected.

- VSD: Very serious defect; defect is too serious to permit operating the car.

The vehicle categories of the Manual are the ones provided by the Directive 2007/46/EC so the vans can be classified in $\mathrm{M} 1$ vehicles and mostly in N1 vehicles. For these ones the inspection frequency indicated in Directive 2009/40 is four years after the date on which the vehicle was first used, and thereafter every two years.

The prescription given by the Directive is nevertheless recommended and not compulsory, each member can thus establish a stricter frequency. This is the case of Spain for N1 vehicles ( $R D$ 711/2006, 2006) as the frequency inspection is two years after the date on which the vehicle was first used, every two years until the sixth year, annually from the sixth to the tenth year and bi-annual after ten years.

\section{Methodology}

The EC Directive 2007/46/EC provides, for the purpose of EU legislation, different categories of vehicles. According to these categories, vans can be classified under:

- Category M1: Vehicles for the carriage of passengers and comprising of not more than eight seats in addition to the driver's seat.

- Category N1: Vehicles for the carriage of goods and having a maximum mass not exceeding 3,5 tonnes. This category is therefore denominated Light Goods Vehicle, LGV henceforth.

The analysis about the influence of van maintenance and roadworthiness on their higher accident ability is carried out by gathering information from different sources:

- The Ministry of Industry annually collects the inspection results of all the vehicle categories M1, N1 and N2 (for the carriage of goods and having a maximum mass 
exceeding 3,5 tonnes but not exceeding 12 tonnes) along with the number of minor (SD) and major defects (SSD and VSD) recorded for each defect Item.

- Information about the defects detected in crash damaged vehicles has been collected from the General Directorate of Traffic of Spain (DGT) for different vehicle types during 6 years (2007-2012).

- An intensive campaign of vans and Light Goods Vehicles (LGV) inspection results throughout different inspection bodies (up to 11.075). Apart from the inspection bulletin, the mileage is also recorded allowing thus to assess the relationship of the vans mobility in their roadworthiness.

- The recommended maintenance schedules by manufacturers of 171 vans of 10 different brands have been collected in order to correlate them with the inspection result.

\subsection{Study of inspection results from the Ministry of Spanish Industry database}

The Ministry of Spanish Industry annually collects the inspection results of all vehicle categories along with the number of minor and major defects recorded for each defect Item.

The statistics provided by the Ministry of Spanish Industry allow comparing the inspection results of $\mathrm{N} 1$ type vehicles with the ones given by $\mathrm{M} 1$ vehicles and $\mathrm{N} 2$ vehicles. A vehicle is considered as rejected if it has one SSD/VSD or more.

In this work, authors analyzed the inspection results during 2007 comparing the rejection index for M1, N1 and N2 vehicles for the whole country. This will allow determining if N1 vehicles have particular defects depending on their typology.

\subsection{Study of defects and age in crash damaged vehicles from the DGT database}

The General Directorate of Traffic (DGT), the Government Department that is responsible for the Spanish transport network, collects information about the possible causes of road accidents. In this study, the information used is related to the defects detected in crash damaged vehicles. Authors analyze the information during 6 years (2007-2012) comparing the defects detected for passenger vehicles, vans, LGV (Light Goods Vehicles) and HGV (Heavy Goods Vehicles) for the whole country. This will allow determining if defects have an influence on the accident rate. Authors also analyzed the age of these vehicles.

\subsection{Study of vans and light goods vehicles according to their age and mileage and their inspection results}

During 2010, 11.075 vans and LGV were analyzed to study their inspection results. In this case, the type of defect is registered for each element inspected.

Another important aspect is to analyze the influence of the van age and mileage on the PMVI results to correlate with its roadworthiness. Mileage was also recorded during these inspections to allow the calculation of the kilometers travelled by the van. According to previous researches (Höhnscheid 2006, Bast 2013), van mobility directly affects the increase of van accidents. 


\subsection{Study of recommended maintenance schedules by manufacturers}

The Maintenance Schedule specifies how often a car should be serviced and what items need attention.

It is probable, that many van owners do not adequately maintain their vehicles or the maintenance programs are not sufficient with the PMVI intervals or with the items inspected. This could affect the roadworthiness of vans. It would be ideal to find ways to get vehicle owners to keep their vehicles continuously in compliance with roadworthiness standards.

In this paper, the recommended maintenance schedules by manufacturers of 171 vans of 10 different brands were collected in order to correlate them with the inspection results. The objective was to analyze the influence of maintenance in the PMVI results.

\section{Results}

\subsection{Main areas of failure at PMVI depending on the vehicle category}

The main areas of failure at PMVI are obtained analyzing the Spanish Ministry database. In this case, a van is considered as rejected if it has one SSD/VSD or more. The rejection percentage in 2007 was about $29 \%, 18 \%$ and $31 \%$ for the M1, N1 and N2 vehicle categories, respectively. The increase of the rejection percentage along with the vehicle mass can be explained by their use rate because $\mathrm{N} 1$ and $\mathrm{N} 2$ vehicles have a commercial and thus more intense use.

The SSD distribution according to the inspection items defined in the inspection manual has been analyzed for every Spanish region finding that for all of them, the higher number of defects occurs in the following Items:

- ITEM 4. Lights and Signal Lights

- ITEM 6. Brakes

- ITEM 8. Axis, wheels, tires and suspension

The order of prevalence of these three Items varies according to the Spanish region and year of study. For $2007,67 \%$ of the Spanish regions recorded the failure in Item 4 (lights and signal lights) as the most important one.

In this project, the same analysis is carried out for vehicles under the M1 and N2 categories. For these vehicles, items 4,6 and 8 are also the prevalent ones with the particularity that item 6 (brakes) is the first SSD/VSD in 100\% of the Spanish regions for N2 vehicles.

Figure 1 shows the percentages of serious defects in the inspected items for vehicles M1, N1 and N2. For M1 vehicles, the item that generates more serious defects is "Item 8: Axis, wheels, tires and suspension" whereas for N2 vehicles the item with higher number of defects is "Item 6: Brakes". This result is concurrent with the fact that brakes are a component in heavy vehicles submitted to a high demand when the vehicle is loaded and thus it is susceptible of higher failure. 
For both N1 and N2 vehicles, "Item 4: Lights and signal lights" is the second item in importance. This item is significantly linked to the owner's concern about maintenance as it reveals that the owner has not taken care of checking and changing the lights if necessary before going to the PMVI.

It can thus be concluded that vans do not present a different typology of defects with respect to other types of vehicles. However, the items showing a higher percentage of serious defects for $\mathrm{N} 1$ vehicles correspond to a percentage value between passenger vehicles and heavy vehicles. For N1 vehicles, the items showing a higher percentage of defects are "Items 4, 6 and 8 ". That is, these vehicles show the most common defects of M1 and N2 vehicles together.

\subsection{Defects detected in crash damaged vehicles from the DGT database}

From the DGT data, defects detected in crash damaged vehicles are analyzed. The information is classified in three main groups:

1. "No defects" when the vehicle does not present any defects, seemingly.

2. "Defects" when the vehicle presents some defects.

3. "Unknown" when it is impossible to know if the vehicle presents any defect.

In Figure 2, the percentage of defects detected in crash damaged vehicles is shown for passenger vehicles, vans-LGV and HGV during 6 years (from 2007 to 2012). The figure indicates that no defects were detected in about $85 \%$ of vehicles for all categories. This shows that not only the defects but also a lot of factors influence accidents, such as, weather, type of road, driver behavior, etc. However, about $1 \%$ can be directly assigned to defects. The average percentage of accidents assigned to defects is $0,82 \%$ for passenger vehicles, $1,28 \%$ for vans and LGV and $1,32 \%$ for HGV. It can be seen that the percentage of accidents due to defects is higher for vans-LGV and HGV.

The statistics of accident causes in Spain are concurrent with the values obtained in other countries. Other authors as Rechnitzer et al (2000), Christensen and Elvik (2006) and Keall et al (2012) have referred to the same problem as in-depth crash investigations are not carried out so the role played by vehicle defects is underestimated. Moreover, crash damages impel an adequate assessment, the exception being the tire conditions that can be easily checked with a visual evaluation.

In Table 1, the type of defects detected in crash damaged vehicles is analyzed. About $25 \%$ of defects are related with "Item 4. Lights and Signal Lights", "Item 6. Brakes", and "Item 8. Axis, wheels, tires and suspension". The average percentage of defects is $20,59 \%, 23,12 \%$ and $34,65 \%$ for passenger vehicles, vans, LGV and HGV, respectively. In Figure 3, the average for 2007-2012 and for each type of defect in passenger vehicles, vans, LGV and HGV is shown. It can be seen that the percentage of total defects detected in crash damaged vehicles is greater in vehicles of the vans, LGV and HGV category. It is remarkable that a characteristic defect in vans and LGV is the overload. This is because the Regulations and road inspections in this type of vehicles are fewer than in HGV. 
Table 1. Percentages of types of defect in crash damaged vehicles

\begin{tabular}{|c|c|c|c|c|c|c|c|c|c|c|c|c|c|c|c|c|c|c|}
\hline & \multicolumn{3}{|c|}{2007} & \multicolumn{3}{|c|}{2008} & \multicolumn{3}{|c|}{2009} & \multicolumn{3}{|c|}{2010} & \multicolumn{3}{|c|}{2011} & \multicolumn{3}{|c|}{2012} \\
\hline & PV & LGV & $\begin{array}{c}\text { HG } \\
\text { V }\end{array}$ & PV & LGV & $\begin{array}{c}\text { HG } \\
\text { V }\end{array}$ & PV & LGV & $\begin{array}{c}\text { HG } \\
\text { V }\end{array}$ & PV & LGV & $\begin{array}{c}\text { HG } \\
\text { V }\end{array}$ & PV & LGV & $\begin{array}{c}\text { HG } \\
\text { V }\end{array}$ & PV & LGV & $\begin{array}{c}\text { HG } \\
\mathrm{V}\end{array}$ \\
\hline Worn tires & 13,1 & 12,4 & 14,4 & 16,6 & 11,0 & 15,6 & 17,0 & 7,6 & 8,2 & 11,1 & 8,6 & 13,4 & 11,8 & 11,7 & 13,7 & 16,7 & 6,6 & 15,4 \\
\hline $\begin{array}{l}\text { Puncture or } \\
\text { blow-out }\end{array}$ & 3,3 & 4,2 & 10,3 & 4,5 & 9,7 & 10,4 & 3,5 & 8,3 & 6,6 & 3,0 & 8,6 & 16,4 & 1,7 & 4,9 & 12,3 & 2,8 & 11,5 & 17,9 \\
\hline tire loss & 0,1 & 0,3 & 1,0 & 0,1 & 0,0 & 2,6 & 0,7 & 1,5 & 4,9 & 0,1 & 1,2 & 0,0 & 0,2 & 0,0 & 1,4 & 0,3 & 0,8 & 1,3 \\
\hline $\begin{array}{l}\text { Deficient } \\
\text { front lights }\end{array}$ & 0,1 & 0,6 & 0,0 & 0,9 & 0,0 & 0,0 & 0,4 & 2,3 & 0,0 & 0,3 & 0,6 & 0,0 & 0,2 & 0,0 & 0,0 & 0,4 & 0,0 & 0,0 \\
\hline $\begin{array}{l}\text { Deficient } \\
\text { rear lights }\end{array}$ & 0,2 & 0,6 & 1,0 & 0,1 & 0,6 & 0,0 & 0,1 & 0,8 & 0,0 & 0,1 & 0,0 & 0,0 & 0,1 & 0,6 & 1,4 & 0,0 & 1,6 & 0,0 \\
\hline $\begin{array}{l}\text { Deficient } \\
\text { brakes }\end{array}$ & 1,4 & 2,8 & 5,2 & 2,6 & 5,2 & 6,5 & 2,1 & 1,5 & 4,9 & 1,2 & 2,5 & 6,0 & 1,3 & 3,7 & 6,8 & 1,1 & 2,5 & 3,8 \\
\hline $\begin{array}{l}\text { Defective } \\
\text { or broken } \\
\text { steering }\end{array}$ & 0,8 & 1,2 & 1,0 & 0,6 & 0,0 & 1,3 & 1,3 & 1,5 & 0,0 & 0,3 & 0,0 & 1,5 & 0,2 & 0,6 & 0,0 & 0,8 & 0,8 & 2,6 \\
\hline Overloaded & 0,1 & 0,3 & 0,0 & 0,4 & 1,3 & 0,0 & 0,0 & 3,0 & 0,0 & 0,3 & 0,6 & 0,0 & 0,1 & 1,2 & 0,0 & 0,3 & 1,6 & 0,0 \\
\hline $\begin{array}{l}\text { Bad } \\
\text { conditioned } \\
\text { load }\end{array}$ & 0,1 & 0,4 & 3,1 & 0,3 & 0,0 & 2,6 & 0,1 & 0,0 & 0,0 & 0,1 & 0,6 & 4,5 & 0,0 & 0,0 & 1,4 & 0,6 & 2,5 & 1,3 \\
\hline $\begin{array}{l}\text { Other } \\
\text { defects }\end{array}$ & 80,5 & 77,4 & 63,9 & 73,8 & 72,3 & 61,0 & 74,8 & 73,5 & 75,4 & 83,6 & 77,2 & 58,2 & 84,3 & 77,3 & 63,0 & 77,0 & 72,1 & 57,7 \\
\hline
\end{tabular}

*PV: Passenger Vehicles, LGV: vans and Light Goods Vehicles, HGV: Heavy Goods Vehicles

In Figure 4, the age of crash damaged vehicles is analyzed for passenger vehicles, vans, LGV and HGV. In this figure, the average of vehicle percentage is depicted during 6 years (20072012). For all types of vehicles the majority of crashes take place when the vehicles are older than 8 years and this could indicate an increase of defects due to lack of maintenance.

It is also observed that the percentage of crashes in vans, LGV and HGV decreases by a considerable amount with respect to passenger vehicles over the vehicle age range (11-15 years). This could be associated with the switch in inspections of 10 year old vehicles from annual to 6-monthly in vans, LGV and HGV, whereas the inspection in passenger vehicles is still annual.

For older vehicles (more than 15 years), the crashes are reduced in all of types of vehicles due to the fact that the owners take care of them.

\subsection{Light goods vehicles mobility and use}

In this research, an average mobility of $28.800 \mathrm{~km}$ per year was recorded for vans and LGV. According to the European Automobile Manufacturers Association (Meninghaus 2011), passenger vehicles had a mobility rate of approximately $15.000 \mathrm{~km}$ per year. A similar value of 
mobility for passenger vehicles in SPAIN is given in (BASMA 2006). The mobility provided in the BASMA project for commercial vehicles (vans, LGV and HGV) is about $72.371 \mathrm{~km}$. Using the mobility calculated in our study for vans and LGV, the mobility for HGV can be estimated at $44.000 \mathrm{~km}$. This result is consistent with the commercial use of vans and light goods transporters. The vans and LGV mobility is halfway between the passenger vehicles and HGV.

Figure 5 represents the mileage with respect to the age of the vehicles at the time of inspection. Each point represents the vehicle average mileage for each vehicle age. From this figure the following parabolic relationship is obtained:

$$
K=751,81 \cdot A^{2}+25.081 \cdot A+22.727
$$

where $\mathrm{K}$ is the mileage and $A$ is the age of the vehicle. The maximum point is settled in 16,68 years and $230.000 \mathrm{~km}$ approximately which suggests an intensive use of the vehicle. From this point, its use diminishes progressively.

The analysis of the 11.075 vans under study according to their age indicates that the density of vans is higher for vehicle ages between 2 and 12 years, showing a maximum value at 11 years of age.

\subsection{Failure according to light goods vehicle age and mileage}

The global result of the 11.075 vans and LGV inspected is that about $38,65 \%$ of them failed the inspection, that is, they had one or more serious defects or very serious defects. This value is $10 \%$ higher than the percentage of failure for all the N1 vehicles inspected in Spain during 2007 and suggests that vans are poorly maintained.

Figure 6 indicates the strong influence of the age of the van in the inspection result as the proportion between failed vs. not failed (no defect and small defect) increases constantly with age (indicated in this case by the first van registration year). It is also noticeable that the number of vans with small defects (SD) is nearly the same as the number of failing vans (SSD/VSD). This indicates that the level of maintenance is thus made but on an inappropriate level.

If statistical analysis is performed according to mileage, and the vans are divided by mileage groups as shown in Figure 7, the distribution reveals that about $69 \%$ of the vans have covered between 50.000 and 250.000 kilometres at the time of inspection which indicates the high mobility of this type of vehicles.

Figure 7 presents the result of the same analysis performed as in Figure 6, but includes mileage distribution. As expected, the higher the mileage is the higher is the proportion of inspections failed.

\subsection{Analysis of failure by item of inspection for light goods vehicles (LGV)}

The items that have caused the vans and LGV to fail inspection are depicted in Figure 8. If they are compared with the national statistics for N1 vehicles, apart from "Item 2: External 
conditioning, car body and chassis" that appears in second place, there is a coincidence in the principal items of failure:

- ITEM 4. Lights and Signal Lights

- ITEM 6. Brakes

- ITEM 8. Axis, wheels, tires and suspension

The results of the 11.075 inspections allow to realize an in depth analysis of each of these items. Tables 1, 2 and 3 represent the number of SSD/VSD registered for each element inspected in items 8, 4 and 6, respectively. The percentage is calculated over the 11.075 inspections in order to indicate the prevalence of a defect within the population under study. It is nevertheless important to note that the same van and LGV could accumulate more than one VSD.

Table 2. Percentage of failure for each element revised in ITEM 8 over the total of inspected vans

\begin{tabular}{ccc}
\cline { 2 - 3 } & No OF SSD/VSD & \% FAILURE \\
\hline AXIS & $\mathbf{5 4 1}$ & $\mathbf{4 , 8 8}$ \\
\hline Front axis or support arm & 193 & 1,74 \\
\hline Rear axis or support arm & 45 & 0,41 \\
\hline Ball bearings & 73 & 0,66 \\
\hline Joints and dust guards & 230 & 2,08 \\
\hline WHEELS & $\mathbf{3}$ & $\mathbf{0 , 0 3}$ \\
\hline wheels & 3 & 0,03 \\
\hline TIRES & $\mathbf{9 8 2}$ & $\mathbf{8 , 8 7}$ \\
\hline Tires & 982 & 8,87 \\
\hline SUSPENSION & $\mathbf{4 1 1}$ & $\mathbf{3 , 7 1}$ \\
\hline Shock absorber & 195 & 1,76 \\
\hline Springs & 13 & 0,12 \\
\hline Torsion and stabilizer bars & 111 & 1,00 \\
\hline Arms, rods and tie rods & 9 & 0,08 \\
\hline Springs and bumpers & 83 & 0,75 \\
\hline
\end{tabular}

It is important to note that the inspection of elements in Item 8 are carried out by the inspector counting on his experience and knowledge in mechanics as they are not using any measuring device (Table 2). The analysis of the results obtained allows observing the following aspects:

- The failure in the front axis is more than four times higher than in the rear axis. This indicates that vans operate at high speeds as in this case the brakes are used more often and the front axis is overexposed due to the load transference to the front axis.

- The failure due to faulty tires comes up with the $50 \%$ of failures in this inspection Item and is close to $10 \%$ over the total of failures.

- In the case of suspension, this kind of inspection is mainly visual as there is no measuring device capable of offering reliable results. This is probably the reason why the number of failures is relatively low. 
The maintenance of these three items is relatively expensive due to the price of the component or the price of manpower. This could explain the behavior of the van owner who is not ready to make big investments in a usually old vehicle.

It is noticeable that the number of total SSD/VSD in Item 4, Table 3, is higher than the ones for Item 6, Table 4, and that the elements of higher failure are used constantly while driving (antidazzle, braking and flasher lights). These results suggest that the van owner is careless about vehicle maintenance although lights are an easy element to repair.

Table 3. Percentage of failure for each element revised in ITEM 4 over the total of inspected vans

\begin{tabular}{ccc} 
& No OF SSD/VSD & \% FAILURE \\
\hline LIGHTS & 669 & $\mathbf{6 , 0 4}$ \\
\hline Fog lights & 134 & 1,21 \\
\hline Main beam lights & 9 & 0,08 \\
\hline Anti-dazzle lights & 386 & 3,49 \\
\hline Dip beam lights & 140 & 1,26 \\
\hline SIGNAL LIGHTS & 824 & $\mathbf{7 , 4 4}$ \\
\hline Horn & 89 & 0,80 \\
\hline Catadioptrics & 76 & 0,69 \\
\hline Braking lights & 256 & 2,31 \\
\hline Flasher lights & 297 & 2,68 \\
\hline Marker lights & 3 & 0,03 \\
\hline Back-up lights & 82 & 0,74 \\
\hline License plate lights & 12 & 0,11 \\
\hline Emergency signal & 8 & 0,07 \\
\hline Specific signal light & 1 & 0,01 \\
\hline
\end{tabular}


Table 4. Percentage of failure for each element revised in ITEM 6 over the total of inspected vans

\begin{tabular}{|c|c|c|}
\hline & № OF SSD/VSD & \% FAILURE \\
\hline BRAKES & 1098 & 9,91 \\
\hline Vacuum pump or compressor and tanks & 1 & 0,01 \\
\hline Cables, bars, levers and connections & 1 & 0,01 \\
\hline Cylinders of the braking system & 7 & 0,06 \\
\hline Discs & 50 & 0,45 \\
\hline Anti-locking device & 4 & 0,04 \\
\hline Brake linings & 30 & 0,27 \\
\hline Parking brake & 218 & 1,97 \\
\hline Service brake & 475 & 4,29 \\
\hline Emergency brake & 1 & 0,01 \\
\hline Brake pedal & 69 & 0,62 \\
\hline Brake servo. Master cylinders & 7 & 0,06 \\
\hline Drums & 13 & 0,12 \\
\hline Flexible/Rigid tubes & 60 & 0,54 \\
\hline Load sensing valve & 162 & 1,46 \\
\hline
\end{tabular}

Among the inspected elements in Item 6, Table 4, it is noticeable that the service brakes compute the higher percentage of failure $4,29 \%$ when it is strongly linked to vehicle safety. The result again suggests that the main interest of the van owner is to exploit the vehicle for transport services even above any safety criteria.

\subsection{Study of recommended maintenance schedules by the manufacturer for light goods vehicles}

The maintenance schedules are carried out keeping three different factors in mind: spatial interval (for a given mileage), temporal interval (for a given time) or whichever of them occurs first.

It is import to remark that while the scheduled recommended by manufacturers are given in time and/or in distance intervals, the PMVI was carried out only in time intervals. 
Van schedules consider 122 check points but the points analyzed were the ones related to the above mentioned items presenting a higher percentage of failure during PMVI, that is, 3 points related to lights and signal lights, 13 points related to brakes and 11 points related to axis, wheels, tires and suspension.

Table 5 shows the types of maintenance analysed for the different points related to brakes. According to the analysis, apart from the replacement of brake fluid and the control on the front and rear brake pads, the majority of schedules do not check points that play a significant role in vehicle safety like leaking brake pipes. If maintenance has been carried out, the schedule is predominantly "whichever occurs first".

Table 5. Types of maintenance schedules for elements related to brakes

\begin{tabular}{lcccc}
\hline & \multicolumn{4}{c}{$\%$ of maintenance schedules } \\
\cline { 2 - 5 } & $\begin{array}{c}\text { Spatial } \\
\text { interval }\end{array}$ & $\begin{array}{c}\text { Temporal } \\
\text { interval }\end{array}$ & $\begin{array}{c}\text { Whichever } \\
\text { occurs first }\end{array}$ & None \\
\hline Replacement & & & & \\
\hline Brake fluid & 9,94 & 28,07 & 61,4 & 0,58 \\
\hline Levels & 29,82 & 0,00 & 48,54 & 21,64 \\
\hline Brake fluid & & & & 7,60 \\
\hline Controls & 37,43 & 0,00 & 54,97 & 7,02 \\
\hline Rear brake pad wear & 29,24 & 0,00 & 63,74 & 66,67 \\
\hline Front brake pad wear & 22,22 & 0,00 & 11,11 & 78,36 \\
\hline $\begin{array}{l}\text { Clips, discs, drums, } \\
\text { canalization }\end{array}$ & 12,28 & 1,17 & 8,19 & 80,12 \\
\hline Hand brake & 17,54 & 1,75 & 30,99 & 92,98 \\
\hline Flexible brake pipes/ clutch & 8,19 & 0,00 & 11,70 & 73,10 \\
\hline Brake pipes (state/leaking) & 7,02 & 0,00 & 0,00 & 76,02 \\
\hline $\begin{array}{l}\text { Front brake pad wear } \\
\text { indicator (functioning) }\end{array}$ & 4,68 & 0,00 & 22,22 & 100,00 \\
\hline $\begin{array}{l}\text { Brake plates (surface } \\
\text { state/depth) }\end{array}$ & 0,58 & 1,17 & 22,22 & 100,00 \\
\hline $\begin{array}{l}\text { Parking brake (functioning) } \\
\text { Brake sharing (regular) }\end{array}$ & 0,00 & 0,00 & 0,00 & \\
\hline $\begin{array}{l}\text { Wheel cylinder / brake } \\
\text { abutment (rubber state) }\end{array}$ & 0,00 & 0,0 & 0,00 & \\
\hline & & & & \\
\hline
\end{tabular}

The same analysis is performed for Item 4, Lights and Signal Lights (Table 6). It is noticeable that the orientation of the lights is not maintained in $80,12 \%$ of the cases when, during PMVI, it is considered as a relevant point to check because it directly affects vehicle safety.

For Item 8, Axis, Wheels, Tires and Suspension (Table 7), it is detected that 8 of the 11 inspection points are only included in $15 \%$ of maintenance schedules (for example, torque nuts, front wheel ball bearings, front arm suspension, etc.). However, an important point such as tyre conditions and pressure is included in the $99,42 \%$ of the schedules. 
Table 6. Types of maintenance schedules for elements related to lights

\begin{tabular}{lcccc}
\hline & \multicolumn{4}{c}{ \% of maintenance schedules } \\
\cline { 2 - 5 } & Spatial interval & $\begin{array}{c}\text { Temporal } \\
\text { interval }\end{array}$ & $\begin{array}{c}\text { Whichever } \\
\text { occurs first }\end{array}$ & None \\
\hline Controls & 27,49 & 0,58 & 61,40 & 10,53 \\
\hline $\begin{array}{l}\text { Exterior lights and signal } \\
\text { lights }\end{array}$ & 14,04 & 1,17 & 38,60 & 46,20 \\
\hline $\begin{array}{l}\text { Acoustic alarms / light } \\
\text { warning / backup light }\end{array}$ & 11,70 & 0,58 & 7,60 & 80,12 \\
\hline Head lamps adjustment & & & & \\
\hline
\end{tabular}

Table 7. Types of maintenance schedules for elements related to axis, wheels, tires and suspensions

\begin{tabular}{|c|c|c|c|c|}
\hline & \multicolumn{4}{|c|}{$\%$ of maintenance schedules } \\
\hline & $\begin{array}{l}\text { Spatial } \\
\text { interval }\end{array}$ & $\begin{array}{l}\text { Temporal } \\
\text { interval }\end{array}$ & $\begin{array}{l}\text { Whichever occurs } \\
\text { first }\end{array}$ & None \\
\hline \multicolumn{5}{|l|}{ Controls } \\
\hline $\begin{array}{l}\text { Shock absorber } \\
\text { (piston rod+ sealing) }\end{array}$ & 25,15 & 1,75 & 29,82 & 43,27 \\
\hline $\begin{array}{l}\text { Tires (condition + } \\
\text { pressure) }\end{array}$ & 32,75 & 0,00 & 66,67 & 0,58 \\
\hline Wheels (torque nuts) & 0,00 & 0,00 & 21,05 & 78,95 \\
\hline $\begin{array}{l}\text { Rear spring clip } \\
\text { (tightening) }\end{array}$ & 0,00 & 0,00 & 2,34 & 97,66 \\
\hline $\begin{array}{l}\text { Front wheel ball } \\
\text { bearings }\end{array}$ & 0,58 & 0,00 & 2,92 & 96,49 \\
\hline $\begin{array}{l}\text { Front/rear } \\
\text { suspensions } \\
\text { (tightening) }\end{array}$ & 0,58 & 1,75 & 12,87 & 84,80 \\
\hline Axis tightening & 0,58 & 0,00 & 0,58 & 98,83 \\
\hline Front axis (visual) & 4,24 & 0,61 & 6,06 & 89,09 \\
\hline Rear axis (visual) & 0,58 & 0,00 & 2,34 & 97,08 \\
\hline $\begin{array}{l}\text { Steering, suspension, } \\
\text { axis }\end{array}$ & 0,00 & 0,00 & 5,26 & 94,74 \\
\hline Front arm suspension & 0,00 & 0,00 & 1,17 & 98,83 \\
\hline
\end{tabular}

\section{Conclusions}

An in depth analysis of the maintenance schedules and the results of the PMVI for vans, LGV and for other vehicles as cars and heavy goods vehicles (HGV) permits us to draw the following conclusions regarding roadworthiness and accidents.

The study reveals that the van and LGV average mobility is $28.000 \mathrm{~km}$ per year. This result concludes that the mobility of these categories of vehicles is halfway between the passenger vehicles and HGV. 
From the inspection of crash damaged vehicles, it concludes that the majority of accidents are not directly related to defects in vehicles (about $85 \%$ ). In the case of vehicles which present defects clearly identified, about $25 \%$ are related to lights, brakes and tires. These elements coincide with the items showing higher level of rejection in PMVI (items 4, 6 and 8). Public Administrations should therefore consider to have higher control in the inspection of these items.

On the other hand, the percentage of defects in crash damaged vehicles is about $58 \%$ higher in vans, LGV and HGV than in passenger vehicles. In the vans, LGV and HGV categories, load is an important defect in crash damaged vehicles. It is remarkable that the defect "overload" is about $1,34 \%$ in vans and LGV but it is not presented in HGV. This is owing to the fact that Regulations and road inspections in this type of vehicles are smaller than in HGV. This conclusion should also be taken into account by Public Administrations.

The percentage of crashes in vans, LGV and HGV decreases by a considerable amount respect to passenger vehicles over the 11-15 year old vehicle age range. This could be associated with the switch from annual to 6-monthly inspections in 10 year old vans, LGV and HGV.

When the Spanish Industry Ministry database is assessed, it is found that the typology of faults in PMVI for vans and LGV do not present different types of failed items with respect to passenger vehicles or HGV. However, the percentage of defects in PMVI is greater in the latter. This tendency is also observed in defects detected in crash damaged vehicles.

The results allow to conclude that in Spain the highest number of defects occurs in items 4 (lights and signal lights), 6 (brakes) and 8 (axis, wheels, tires and suspension) for vehicles of the M1 and N2 categories. These results are consistent with other results obtained in other European countries (Dahl Göran 2007).

Moreover, the present study has found that the percentage of failure for $\mathrm{N} 1(38,65 \%)$ is $10 \%$ higher than the M1. This seems to manifest the singularity of this vehicle as it is driven like a car, in terms of speed and driver skills, but the usually intensive commercial use lessens the roadworthiness of the van to the heavy vehicle state.

Considering the PMVI results, "Item 4: Lights and signal lights" is the second item with more failures. As these components can be easily checked by van drivers or owners, this could manifest that they are not taking their van maintenance seriously.

Another relevant conclusion from this study is that the maintenance schedules are not homogenous between different brands and types. They can lack checking points that are important for vehicle safety like leakages and the orientation of the lights. They also mean an investment in time and money and not being compulsory, the van owner tries to reduce it to the minimum in order to get the maximum profit from the vehicle. 


\section{Acknowledgements}

Authors gratefully acknowledge the funds provided by the Spanish Government through the research project FURGOSEG - P24/08 "Development and application of an integrate methodology for the study of the traffic accidents with LTVs involved", of the Spanish National Research Plan 2008-2011.

\section{References}

Aparicio Izquierdo F, Arenas Ramírez B, Mira McWilliams J.M, Páez Ayuso. J. 2011. The endurance of the effects of the penalty point system in Spain three years after. Main influencing factors. Accident Analysis \& Prevention. Volume 43, Issue 3, 911-922. http://dx.doi.org/10.1016/j.aap.2010.11.014.

AUTOFORE. 2006. Current Situation and Trends in Roadworthiness Enforcement. Study on the Future Options for Roadworthiness Enforcement in the European Union. http://www.citaVehicleinspection.org/Portals/cita/autofore_study/LinkedDocuments/Literature\%20research.p df

BASMA. 2006. "Informe BASMA 2006. Disposición básica del Parque Rodante ante la seguridad $y$ el Medio Ambiente". FITSA. https://espacioseguro.com/fundacionfitsa0/admin/fitsa/ archivos/ publicaciones/0000016/Informe\%20BASMA.pdf

Bast, DEKRA, UDV and VDA. Project Report: Safety of Light Commercial Vehicle. Published by www.VDA.de. 2013.

Christensen P, Elvik R (2006) Effects on accidents of periodic motor vehicle inspection in Norway, Accident Analysis and Prevention 39:pp. 47-52.

Dadashova B, Arenas Ramirez B, Mira McWilliams J.M and Aparicio Izquierdo F. 2012. Dynamic statical model selection: application to traffic accident analysis in Spain. Procedia - Social and Behavioral Sciences, Volume 48, 642-652. http://dx.doi.org/10.1016/j.sbspro.2012.06.1042.

DGT. http://www.dgt.es/es/seguridad-vial/estadisticas-e-indicadores/publicaciones/anuarioestadistico-accidentes/

FEMA, 2013. Periodical Technical Inspection Data collection. An overview of available data. http://www.fema-online.eu/uploads/PTI-Alternative Data.pdf

Höhnscheid et al. 2006. IMPROVER Final report.Impact assessment of measures concerning the improvement of road safety of light goods vehicles (LGV) Subproject 2. http://ec.europa.eu/transport/roadsafety_library/publications/improver_final_report_sp2_06 0430.pdf.

Keall, M; Stephan, K; Watson, L; Newstead, S (2012) Road safety benefits of vehicle roadworthiness inspections in New Zealand and Victoria. Monash University Accident Research Centre. Report no 314. 
Krueger, L. 2005. Roadworthiness Enforcement Different Concepts and their Assessment. Dissertation. At the study academy Horb am Neckar, Germany.

Martinez, J. 2009. Una accidentabilidad emergente. Tráfico y seguridad víal no 196, 44.45. Spanish General Traffic Directorate. ISSN 1886-3566

Meninghaus, R. 2009. The role of public procurement for the market entry of clean and energy-efficient mobility solutions. Conference on Urban Mobility (in association with the European Sustainable Energy Week) Brussels, 11 February 2009. http://ec.europa.eu/transport/urban/events/doc/2009_02_11_presentation_meininghaus.pdf

Molinero et al. 2008. TRACE Project No.FP6-2004-IST-4 027763 Deliverable 1.1 Road users and accident causation. Part 1: Overview and general statistics. http://www.traceproject.org/publication/archives/tracewp1d1-2-v2.pdf. Accessed April 2012

Rechnitzer, G., Haworth, N., Kowadlo, N. 2000. The effect of vehicle roadworthiness on crash incidence and severity. Monash University Accident Research Centre. Report no 164. http://www.monash.edu.au/miri/research/reports/muarc164.pdf. Accessed April 2012

Tanaboriboon Y, Kronprasert N, Khompratya T, Suanpaga V, Chanwannnakul T, Taneerananon $P$ (2005) An evaluation of the effectiveness of the private vehicle inspection process in Thailand, Journal of Eastern Asia Society for Transportation Studies 6:pp. 3482-3496.

Van Schoor, O., van Niekerk, J.L., Grobbelaar, B. 2001 Mechanical failures as a contributing cause to motor vehicle accidents- South Africa. Accident Analysis and Prevention 33, 713-721. http://dx.doi.org/10.1016/S0001-4575(00)00083-X.

DIRECTIVE 2009/40/EC OF THE EUROPEAN PARLIAMENT AND OF THE COUNCIL of 6 May 2009 on roadworthiness tests for motor vehicles and their trailers

Real Decreto 711/2006, de 9 de junio, por el que se modifican determinados reales decretos relativos a la inspección técnica de vehículos (ITV) y a la homologación de vehículos, sus partes y piezas, y se modifica, asimismo, el Reglamento General de Vehículos, aprobado por Real Decreto 2822/1998, de 23 de diciembre.

\section{List of figures}

Figure 1. Percentages of SSD/VSD for vehicle categories M1, N1 and N2

Figure 2. Percentage of defects detected in crash damaged vehicles (PV: Passenger Vehicles, LGV: Vans and Light Goods Vehicles, HGV: Heavy Goods Vehicles)

Figure 3. Average of percentage for each type of defect in crash damaged vehicle

Figure 4. Percentage averages for crash damaged vehicles depending on their age

Figure 5. Relationship of total mileage with respect to vehicle age for vans

Figure 6. Results of vehicle inspection for vans according to the registration year

Figure 7. Inspection result for vans according to the type of defect and mileage 
Figure 8. Percentage of failure according to item of inspection 